\title{
Complejos termales en las villae tardorromanas del Camp de Tarragona (Ager Tarraconensis)
}

\author{
Lluís Piñol Masgoret * \\ Jordi López Vilar ***
}

\begin{abstract}
RESUMEN
Presentamos los complejos termales asociados a villae tardías hallados hasta la actualidad en el Camp de Tarragona. Asimismo se hace un breve análisis comparativo de las relaciones ciudad-campo y termas-villae desde época tardo-republicana hasta el siglo VIII, prestando una especial atención a la fase tardorromana.
\end{abstract}

PALABRAS CLAVE: Villa. Complejos termales. Ager Tarraconensis. Antigüedad tardía.

\section{INTRODUCCIÓN}

En el análisis del paso de la época alto imperial a la antigüedad tardía, en un campo de estudio tan concreto como el de los complejos termales, no se puede pasar por alto la influencia de los factores sociales, políticos y económicos generales en la paulatina transformación de la sociedad romana. En efecto, todos ellos no solamente afectaron de forma directa el aspecto concreto del ritual del baño, claramente marcado, por ejemplo, por la implantación del cristianismo, sinó que también influyeron de forma sustancial, o incluso en algunos casos determinante, en la evolución de

\begin{abstract}
We present here a relation of the termal complexes associated at late roman villae, found in the Camp of Tarragona. Also we realise a comparative analysis about the relations between city and country and between thermae and villae since republican period to the VIII century, with special emphasis to the late roman period.
\end{abstract}

KEY WORDS: Villa. Termal complexes. Ager Tarraconensis. Late antiguity.

los recintos termales entendidos como unidades arquitectónicas (Yegül 1992). Es por ello que no podemos hacer una generalización para todos los territorios sobre la implantación o evolución de los complejos termales en época tardía ya que los factores que confluyen son múltiples, variados y, en algunos casos, específicos de cada zona.

En el momento de llevar a cabo el análisis de un territorio determinado es necesario plantear la problemática en la que éste se ha visto inmerso. Desde este punto de vista, es obvio por los datos de que hoy disponemos que la investigación que se ha realizado hasta la actua-

* Institut d'Arqueologia i Estudis del Món Antic. Universidad Rovira i Virgili. Tarragona.

*** Servei Arqueològic. Universidad Rovira i Virgili. Tarragona. 
lidad ha sido desigual. Conocemos un gran número de yacimientos gracias a hallazgos casuales y a prospecciones a pequeña escala de algunas partes del territorio, hechas por eruditos o investigadores locales a lo largo de esta última centuria. A ello se unen unas pocas prospecciones sistemáticas de una parte del territorio, en especial las llevadas a cabo por el equipo formado por J.Ma. Carreté, S. Keay y M. Millett entre los años 1985 y 1990 (CARRETÉ, KEAY, MILLETT 1995). El desarrollo industrial y económico de todo el territorio, iniciado a finales de los cincuenta, ha impulsado el crecimiento de muchos núcleos urbanos y un rapidísimo proceso de ocupación con finalidades industriales, mercantiles o turísticas de espacios que hasta hace pocos años eran terrenos yermos, forestales o agrícolas. A ello se ha añadido un importante desarrollo de las infraestructuras que ha acabado por transformar radicalmente el paisaje. Por desgracia, en algunos casos, el avance de la ciencia arqueológica no ha ido del todo ligado a la concienciación ciudadana y a una actuación administrativa lo suficientemente efectiva. Aunque se han dado pasos importantes como la elaboración de cartas arqueológicas comarcales, éstas han servido en la mayoría de los casos para preservar, más o menos, los yacimientos ya catalogados sin tener en cuenta que amplias zonas del territorio estaban aún por prospectar y, por lo tanto, eran parcial o totalmente desconocidas. La ciudad y su territorio han adolecido desde el punto de vista administrativo de una política de prevención tanto por parte del ente autónomo como de los propios municipios. No hay aún hoy una conciencia del rico patrimonio histórico y arqueológico que se posee y se sigue actuando más como respuesta a hechos consumados que con una visión organizada y estructurada de las cosas. Cierto es que hoy hay a disposición de los investigadores un caudal de información del que carecíamos años atrás pero no es menos cierto que se ha perdido para siempre la posibilidad de conocer muchos otros datos. En cierta medida se han primado los intereses económicos por encima de los científicos, sin darse cuenta que ambos pueden ser y son compatibles. En los últimos años se han iniciado campañas de excavación en algunos de los yacimientos rurales conocidos (La Llosa, el Moro, Els Munts, o Callípolis), que sin duda proporcionaran en el futuro datos sobre su estructura y evolución, pero aún así seguirá faltando una visión de conjunto fiable como muy bien recalcaron S. Keay y sus colaboradores: "without systematic surface survey one is clearly unable to gain any idea of the density of rural settlement or its development" (CARRETÉ, KEAY, MILLETT 1995: 33). Así pues, el territorio de la Tarraco romana sigue siendo hoy, desde un punto de vista espacial y no específico de un yacimiento en concreto, el gran desconocido a pesar del potencial de conocimiento histórico que a partir de su estudio se podría obtener.

\section{EVOLUCIÓN DEL POBLAMIENTO RURAL EN EL TERRITORIUM DE TARRACO}

Los límites generales del hinterland de Tarraco no nos son conocidos con exactitud. Una primera hipótesis sugería el arco de Bará como marca del extremo norte (NIERHAUS 1964). Actualmente este planteamiento ha sido desestimado y se tiende a buscar en los accidentes geográficos los verdaderos delimitadores del espacio físico dependiente de Tarraco. De esta forma, el límite norte se encontraría en el punto donde cierra el macizo del Garraf, en la intersección de los ríos Anoia y Llobregat, en Martorell (DUPRÉ 1994: 276-277; CARRETÉ, KEAY, MILLETT 1995: 33). El sur se situa justo donde la sierra de Tivissa penetra hacia el mar, cerca de L'Hospitalet de l'Infant. Finalmente el territorio estaría delimitado hacia el interior por la Sierra de Prades, que marca la separación entre la llanura costera y los ricos campos de cultivo de la actual provincia de Lleida. Así pues, el ager Tarraconensis se extendería por las actuales comarcas que forman el Camp de Tarragona y el Penedès.

La ciudad se emplazó desde su fundación en el 218 a. C. en un promontorio muy próximo a la costa, un enclave estratégico por su proximidad al Ebro, por la existencia de un puerto natural y por el control visual del entorno circundante. Dos ríos procedentes de las sierras cercanas desembocan en las costas veci- 
nas. El río Gaià, al norte de la ciudad, y el Francolí -el antiguo Tulcis-, situado al sur y a escasa distancia de la misma.

Estudios parciales desarrollados en la comarca del Penedès han permitido plantear una primera hipótesis de evolución del territorio. De esta forma, la llegada del mundo romano no supuso una ruptura con el elemento indígena sinó más bien una continuidad de los núcleos ibéricos hasta los siglos II y I a. C., momento en que fueron gradualmente desapareciendo para dar paso a los primeros establecimientos rurales romanos, documentados a partir de la segunda mitad del siglo II a. C. (MIRET, SANTMARTI, SANTACANA 1991: 47-50).

En el entorno más cercano a la urbe parece intuirse el mismo fenómeno. Los datos conocidos nos muestran una ocupación del territorio en época tardo-republicana por medio de pequeños establecimientos rurales del tipo granja I y la aparición de las primeras villae? . A lo largo de la época augustea se detectan cambios importantes en los patrones de ocupación del mismo. A partir de este momento se abandonará un número importante de estos establecimientos rurales ${ }^{3}$ mientras que otros serán el embrión de las villae alto imperiales que rápidamente articularan el ager ${ }^{4}$. La aparición de las explotaciones agrarias del tipo villa se ha relacionado generalmente con el inicio de una explotación intensiva del territorio orientada a la producción de un excedente lo suficientemente importante como para ser susceptible de exportación. Tarraco fue conocida por la producción de unos vinos de excelente calidad ${ }^{5}$. Actualmente se acepta que esta producción comenzó inicialmente en la región Layetana (MIRÓ 1988, 60; REVILLA 1993, 314; OLESTI, 1997) y no llegó hasta nuestro territorio hasta finales del siglo I a. C., siendo el siglo I d. C. el período de máximo esplendor. Se cree que algunas producciones perduraron hasta muy avanzado el siglo III.

Este panorama aparentemente homogéneo no lo es tanto cuando se profundiza un poco en los datos disponibles. Junto a estas villae se detectan pequeños establecimientos agrarios o industriales que podrían funcionar dependiendo de un fundus o de forma independiente ${ }^{6}$.

En general las villae se dotaran de un sector residencial en el que se intentará reproducir el modus vivendi de la ciudad. Se generalizará, pues, a partir de este momento la presencia de conjuntos termales integrados en la pars urbana. Se trata en general de pequeños complejos que siguen un esquema de tipo lineal en sus diversas variantes o, en algún caso, axial. A este sector residencial se le unirá un amplio conjunto de estructuras productivas en función de la importancia y dimensiones del fundus (alfa-

\footnotetext{
I Un ejemplo de este tipo de establecimientos lo tenemos en el yacimiento romano de la Clota (Creixell) donde se documentó un edificio de planta rectangular de $90 \mathrm{~m} 2$ articulado en cinco espacios o habitaciones pavimentadas en algunos casos con opus signinum y en otros con suelos de tierra batida. Asimismo las paredes de algunas de ellas presentaban estuco o la preparación del mismo. Sus excavadores datan el momento de construcción a finales del siglo II a.C. y el momento de su abandono en el s. I a.C. El edificio sufrió, en un momento indeterminado y antes de su abandono definitivo, una reforma orientada a una nueva distribución de algunos de sus espacios internos (Vilaseca, Carilla 1998: 190-194).

2 Es el caso de la primera fase de la villa de El Moro en Torredembarra.

3 Las prospecciones en superficie llevadas a cabo en zonas próximas al río Gaià nos muestran la presencia de pequeños núcleos rurales cuyo material no supera, en principio, la época augustea. Ahora bien, el hecho que ninguno de ellos haya sido, hoy por hoy, objeto de una excavación sistemática nos hace mantener una cierta prudencia y considerar este planteamiento sólo como una base de trabajo.

4 Es el caso por ejemplo del yacimiento de El Moro donde en época augustea se detecta una reestructuración muy importante del asentamiento. Las estructuras tardo-republicanas son desmanteladas sirviendo de cimentación a nuevas construcciones articuladas entorno a un peristilo (Terré 1987; Piñol 1996). Cambios también importantes se detectan en otras explotaciones agrarias del Camp de Tarragona que muestran una continuidad de ocupación desde época republicana. Son los casos de las villae de Centcelles, en Constantí (Hauschild, Arbeiter 1993: 29-31) o de otros establecimientos de los que tenemos una menor información como la villa de Les Cavalleries en Vallmoll (Macías, J. Ma 1996).

5 Las fuentes están recogidas en las Fontes Hispaniae Antiquae y son estudiadas en diversas publicaciones (Miró 1985; Revilla, 1995: 305-309).

6 Nos queda mucho aún hoy para llegar a comprender los patrones que rigieron la explotación del territorio así como las estructu-
} ras de producción y las relaciones económicas provinciales. 
res, depósitos, instalaciones para la manufactura de los productos agrícolas, almacenes, etc.) (REVILLA 1993; Idem 1995: 31 I).

Se ha planteado el siglo III como el punto de partida de una serie de importantes cambios que supusieron el paso de la ciudad altoimperial a la tardorromana y una importante transformación de los patrones de asentamiento en el ager. De esta forma las villae se convirtieron en centros de explotación, producción y hábitat (ARCE 1986).

\section{LA CIUDAD Y EL CAMPO EN ÉPOCA TARDÍA}

Tenemos aún hoy pocas evidencias de la estructura urbana de la ciudad de Tarraco en el siglo IV. Desde un punto de vista arqueológico se muestra una modificación importante de la estructura urbanística de la misma. Toda el área residencial de época tardo-republicana y altoimperial quedó, al menos, parcialmente amortizada como resultado, entre otros factores, de una decadencia de los órganos de administración local que condujo a un abandono de las infraestructuras urbanas y de las áreas residenciales tradicionales (ADSERIAS, M. et alii 1997). Por el contrario la epigrafía, aunque escasa, nos muestra una cierta actividad edilicia orientada a la reparación o adecuación de espacios públi$\cos ^{7}$ y una cierta actividad evergética de la administración provincial a lo largo de la primera mitad del siglo IV (ARCE 1994: 152). Parece pues que al menos a inicios del siglo IV la ciudad mantuvo una cierta vitalidad. Por otra parte, los datos de los que hoy se dispone tienden a mostrarnos una concentración de la población y una bipolarización de la misma en dos áreas concretas a partir, posiblemente, de finales del siglo
IV o inicios del siglo V: la parte alta de la ciudad (antiguo Foro Provincial y circo) y el entorno del puerto, donde surge un importante núcleo de ocupación suburbana no muy lejos de la basilica paleocristiana y el área de necrópolis del Francolí (DEL AMO 1979) y de las estructuras tardías localizadas en Parc Central (LÓPEZ 1997). Este fenómeno se consolidó con una restauración del circuíto murario que protegía el núcleo urbano en torno al 475-550 (HAUSCHILD 1983; MACIAS 1999: 231), hecho éste que se constata en muchas otras ciudades hispanas ${ }^{8}$.

El puerto de Tarraco gozó de una gran vitalidad en época tardorromana, convirtiéndose en el punto de entrada de productos e influencias. Este hecho pone de manifiesto que la ciudad se mantuvo como centro de comercio aunque lo que evidencia el registro arqueológico es que los centros exportadores ya no eran, en su mayor parte, los mismos que en época anterior (REMOLÀ 2000).

Así pues, Tarraco siguió funcionando como centro redistribuidor de productos llegados de otras provincias del Imperio. De esta forma, los canales de distribución hacia las ciudades del interior se mantuvieron más o menos constantes hasta mediados del siglo $\vee$ d.C., tal como se pone de manifiesto en diversas excavaciones de llerda (PÉREZ 1997: 607). Será pues a partir de este momento cuando la trama comercial entre costa e interior quedará interrumpida. Estos datos contrastan de forma significativa con lo que sucede en la ciudad, donde la presencia de importaciones es contínua hasta inicios del siglo VIII (AQUILUÉ 1991; REMOLÀ 2000).

En el ager, después del impás del siglo III en el que se detecta el abandono de un número significativo de establecimientos alto imperiales ${ }^{9}$,

\footnotetext{
7 Para el tema que tratamos es especialmente significativa la inscripción RIT I55, que conmemora la reconstrucción de las Thermae Montanae a cargo de Marcus Aurelius Vicentius, gobernador - praeses- de la provincia. El dedicante es Messius Marianus, curator reipublicae Tarraconensis. Se trata de unas termas que sin duda llevan el nombre de su antiguo patrono, un tal Montanus. A nivel arqueológico también hay que destacar las recientemente halladas termas públicas de la calle Sant Miquel, que siguieron en funcionamiento, según parece, en el Bajo Imperio. Igualmente, se conocen pequeños conjuntos termales datados en época tardía asociados a domus, como los hallados en la calle Felip Pedrell o en Parc Central.

8 A partir del siglo $V$ se detectan importantes obras de construcción o reforma de los lienzos murarios de muchas ciudades hispanas (Hauschild 1994). Asimismo también se detecta una reducción generalizada en la extensión del núcleo urbano, que tiende a concentrarse en puntos altos para favorecer su defensa. Es el caso de ciudades como llerda (Pérez 1997) o Lucentum (Reynolds 1987; Rosser, 1994).
} 
el siglo IV supuso un período de resurgimiento o recuperación de las estructuras agrarias. Algunas de las villae sufrieron cambios, reocupándose nuevamente bajo otros patrones y modificando así sus dimensiones, estructura y funciones. Cabe situar en esta época, pues, el inicio de la evolución en las estructuras de explotación del territorio, caracterizado por una concentración de la propiedad, lo cual no es sinónimo de decadencia sino todo lo contrario. A lo largo de esta última centuria muchos de estos establecimientos gozarán de una importante vitalidad, construyéndose lujosos edificios decorados con mosaicos y pinturas murales y donde el sector residencial seguirá manteniendo un destacado papel, como queda plasmado con la presencia de peristilos, patios o termas. Cabe también destacar la proliferación de espacios con cabeceras semicirculares o poligonales, poco comunes en la época anterior (CHAVARRIA 1996: 172).

No son muchos los datos de los que disponemos para la demarcación que estudiamos ya que la mayoría de los yacimientos conocidos lo son a partir del material de superficie. Pero todo parece indicar que no se trata de establecimientos ex novo sino que son generalmente villae alto-imperiales que se trasforman o se reestructuran adaptándose a los nuevos tiempos. Por lo tanto, y en general, presentan unas características idénticas de localización en el territorio respecto a las de época anterior. Entre ellas cabe destacar por su importancia: su emplazamiento en lugares de fácil comunicación, ya sea terrestre o por mar; su proximidad a cursos de agua dulce, ya sean continuos o estacionales; y el aprovechamiento de los terrenos más aptos para el cultivo. Es el caso de villae como Centcelles, Els Munts, Callípolis, Paret Delgada, Les Cavalleries, etc.

Generalmente se ha tendido a ver en este período una serie de procesos orientados a la ruralización de la sociedad hispano-romana reflejados en el abandono de la ciudad por parte de las clases dirigentes y en una progresiva autarquía de las villae respecto a los núcleos urbanos, con la consecuente reducción de los intercambios. Según estas hipótesis se creó una tendencia hacia la concentración de las propiedades y una evolución encaminada a una economía de autosuficiencia. Keay sitúa estos cambios en el siglo IV (KEAY 1984: 557-558; Idem 1987: 386-288), mientas que otros autores los localizan a partir la segunda mitad del mismo siglo (JÁRREGA 1997).

Estos procesos hasta cierto punto son ciertos pero no se puede para esta época generalizar conceptos ya que la incidencia de diversos factores tanto locales como generales pudieron actuar de forma diversa según la ciudad de la que estemos hablando y en función también del momento cronológico. No se puede negar la evolución de la sociedad romana a partir del siglo III i especialmente el IV; la consolidación del cristianismo, la creación de una nueva estructura social y el creciente aumento del poder de unas nuevas élites dirigentes no supuso, al menos para el siglo IV, una ruptura de la relación campo-ciudad. Muchos de los possessores de las villae del momento formaron parte de la aristocracia municipal o fueron altos cargos religiosos ${ }^{10}$.

\section{COMPLEJOS TERMALES TARDORROMANOS EN VILLAE TARRACONENSES}

La villa romana de Centcelles (Constanti) disfrutó de un período de ocupación que se prolonga desde época tardo-republicana (II-I a. C.) hasta época bajo-medieval. A lo largo de todo este tiempo el establecimiento pasó por diversas reformas, reestructuraciones e incluso momentos de abandono (HAUSCHILD, SCHLUNK 1986; HAUSCHILD, ARBEITER 1993). La fase

\footnotetext{
9 Por ejemplo la villa de Mas d'en Gras, Vila-seca (Sánchez 1996).

10 Se ha planteado para el caso de Centcelles una nueva hipótesis, según la cual el personaje a quien se dedicó la cúpula no fue Constante, hijo de Contantino, sino un alto personaje eclesiástico cristiano, posiblemente un obispo (Arce 1994: 157).
} 
de ocupación mejor conocida es la perteneciente a mediados del siglo $\mathrm{IV}$, momento en que se amortizan una serie de estructuras anteriores y se erige un nuevo edificio concebido como una villa porticada que sufrió importantes cambios ya desde un primer momento. El sector residencial estaría formado por un mínimo de seis estancias que toman como eje constructivo una estructura absidial dividida en dos salas accesibles desde el pórtico. Todas ellas sufrieron profundas reutilizaciones por lo que es difícil saber la funcionalidad para la que fueron concebidas. A pesar de ello, las características arquitectónicas de las dos dependencias centrales así como sus dimensiones hacen pensar en los espacios de representación del propietario de la villa. Al oeste del sector residencial se proyectó y construyó en este momento un complejo termal de grandes dimensiones formado por 16 estancias al que se accedía también desde el pórtico.

Todo parece indicar que antes de que los diferentes sectores de la villa fueran acabados de construir sucedió algún hecho que conllevó un cambio funcional de los mismos. Generalmente se ha achacado esta reestructuración a la muerte del propietario. En este momento una de las salas circulares cubierta con cúpula se transformó en mausoleo, decorándose con magníicos mosaicos de temática cristiana. Por otra parte, los datos proporcionados por las excavaciones del Instituto Arqueológico Alemán parecen indicar que el sector termal en construcción no fue acabado, sufriendo importantes cambios en algunos de sus espacios, que pasaron a funcionar como taller "'. En contraprestación se construyó un nuevo edificio termal de menores dimensiones y que seguramente se adecuaba mejor a la nueva situación. Estas termas sí que fueron utilizadas tal y como queda patente por los signos de combustión hallados en los hipocaustos del sector calefactado de las mismas.
El primer complejo termal estaría formado, como ya hemos dicho, por un total de 16 ámbitos que se suceden de este a oeste formando una estructura alargada de poco más de $50 \mathrm{~m}$. Trece de las mismas fueron construídas en un primer momento, mientras que las tres restantes se añadieron con posterioridad, seguramente cuando el edificio había ya cambiado de funcionalidad, aunque se mantuvo la estructura. Este edificio termal se concibió con un esquema de tipo anular simple (BRODNER 1983: 29; CICERCHIA 1984: 48) o ringtyp, que prevé una circulación en un único sentido y siguiendo una directriz circular. Se trata en general de un esquema típico de complejos termales urbanos y rurales de medianas dimensiones.

A pesar de que diferentes aspectos dificultan la interpretación ${ }^{12}$ de alguna de las estancias que forman parte del edificio, su articulación parece clara. El acceso desde el pórtico se efectuaría a través de una puerta abierta en el lado sur de la habitación que funcionaría como apodyterium (A). Esta sala dispondría de un espacio anejo de difícil adscripción. A través de una puerta situada en el muro oeste se entraría en el frigidarium (F). Se trata de la sala más grande del complejo que presenta una planta rectangular orientada de este a oeste. En el centro de la misma y siguiendo la misma dirección se halla una canalización de desagüe del pavimento, que nunca se llegó a utilizar. A este espacio central se abren seis salas más pequeñas, tres al norte, pertenecientes a la primera fase, y otras tres al sur, construídas con posterioridad. A pesar de esta diferenciación temporal, todas ellas presentan las mismas dimensiones, exceptuando las dos centrales de cada lado, que son algo mayores. Este tipo de estructura no es desconocido en el mundo termal de época romana; está presente, por ejemplo, en el frigidarium de las termas de Diocleciano en Roma o en las del Foro de Ostia. Fue precisamente este sector el que

\footnotetext{
I I Para datos arqueológicos, análisis de los cambios que afectaron a este sector y diferentes hipótesis de interpretación ver: Hauschild, Arbeiter 1993; Piñol 1993.

12 Para un análisis más pormenorizado de esta hipótesis de interpretación ver Piñol 1993.
} 
quedó inacabado y fue utilizado con otro destino. La estratigrafía de las salas del lado norte así lo de- muestra; sobre un nivel de construcción, se documentó un segundo estrato de uso formado por teselas sin utilizar, trozos de mármoles y piedras de colores diferentes que nos demuestran su utilización como taller para la construcción de los mosaicos de la cúpula (HAUSCHILD 1965; HAUSCHILD, SCHLUNK 1986: 6).

Desde el frigidarium se accedía al sector caliente del edificio. Una puerta situada en el lado oeste comunicaría con el tepidarium $(T)$ del complejo. Seguidamente se accedería a otra sala de similares dimensiones identificada como una sudatio (S), que dispondría de una estructura absidial en el lado sur. Finalmente encontraríamos el caldarium (C). Éste está formado por una habitación de planta cuadrangular a la que se abren tres alvea (al), dos de forma rectangular en los lados norte y sur y otro absidial en el lado oeste. Respecto a las zonas de servicio solamente se ha localizado hasta hoy una entrada de praefurnium que comunicaba con el hipocausto del tepidarium. Hemos de suponer que detrás de uno o más de los alvea del caldarium habría más praefurnia, si es que realmente se llegaron a construir.

Desde la sudatio se accedería, como camino de retorno al frigidarium, a otras dos salas simétricas a las del lado sur (tepidarium y sudatio) pero que en este caso no dispondrían de hipocausto. Ambas se encuentran muy arrasadas. En un primer momento fueron interpretadas como el frigidarium del recinto (HAUSCHID, ARBEITER 1993: 12), pero sus características concretas y su relación con las estructuras anejas niegan esta posibilidad (PIÑOL 1993: 92). Su identificación a pesar de ello es difícil de establecer.

El segundo complejo termal está constituido por cuatro estancias. Se accede a él desde el pórtico mediante una puerta abierta en el muro este de la habitación que cumple la función de apodyterium/frigidarium (A/F). La piscina $(\mathrm{Pi})$ del sector frío, provista de cabecera semicircular, se encuentra en el lado sur.
La comunicación con el área caliente se efectuaba a través de una puerta no conservada situada en el muro oeste de la habitación. Este sector estaba formado por dos estancias de forma cuadrangular y de pequeñas dimensiones que presentan hipocausto. Primero encontramos el tepidarium ( $T$ ) que disponía de dos pequeñas bañeras individuales (al). Desde el tepidarium se pasaba al caldarium (C), que estaba provisto de un único alveus (al) en su lado sur. Todos los hipocaustos eran calentados desde un praefurnium $(\mathrm{Pr})$ emplazado al oeste del caldarium.

Nos encontramos, pues, ante un complejo termal de pequeñas dimensiones que sigue un esquema axial de tipo simple, también conocido como reihentyp (BRODNER 1983: 39; CICERCHIA 1986: 48), que se caracteriza por tener que seguir el mismo recorrido tanto de entrada como de retorno. Integradas en el conjunto se conservan las letrinas. A ellas no se accedía desde el conjunto termal sino desde un posible corredor aún pendiente de excavación.

La villa romana de Callípolis se encuentra ubicada en el término municipal de Vila-seca, junto al mar y a unos 8 kilómetros de Tarragona. El interés por estos restos nació a raíz de los esfuerzos de los eruditos locales para encontrar la Callípolis citada en la Ora Marítima de Rufo Festo Avieno. Aunque la mítica ciudad no fue hallada, sí se localizó una villa romana de gran extensión, en la que se realizaron los primeros sondeos entre 1955 y 1956 (SÁNCHEZ 1990). En 1960 se extrajo el magnífico mosaico de los peces, que por su interés ha merecido un estudio monográfico (BALIL-MONDELO 1985). Desde aquellas fechas, diversos sectores del yacimiento han sido afectados, bien por conducciones de tipo industrial, bien por las obras del cámping que se construyó encima. En el año 199| se iniciaron una serie de campañas sistemáticas que han llevado a la excavación de una parte considerable de la villa. Actualmente tenemos un mejor conocimiento de la evolución y estructura del edificio gracias a estos trabajos, cuyos resultados han sido parcialmente publicados (MACÍAS-TUSET 1995). 
La etapa fundacional es la más desconocida, debido a los escasos restos conservados y a la proximidad del nivel freático que dificulta enormemente la excavación de las capas más profundas de la estratigrafía, pero debe situarse en el siglo I d.C. No obstante, la presencia descontextualizada de cerámicas más antiguas hace sospechar un origen anterior. La mayor parte de las construcciones conservadas corresponden a principios del siglo II, momento en el que se construye la gran villa, articulada en torno a un patio en forma de $U$ que mide unos $50 \times 35$ metros. En cada una de las tres alas se concentran los diferentes ámbitos, de carácter residencial unos y rústico otros. Las termas, construidas a la par que todo el edificio, se ubican en la parte más meridional. En el transcurso del tiempo se producirán reformas que supondrán la transformación de determinados espacios. Así, se detecta a partir del Bajo Imperio el abandono de ciertos espacios periféricos de la villa y una progresiva reducción del espacio edificado, que se concentrará ahora en la antigua parte residencial, donde las estructuras arquitectónicas son más importantes. A pesar del estado de arrasamiento de los estratos superiores -los más tardíos- se detecta una pervivencia, al menos, hasta el siglo Vl. (MACÍAS 1999).

Se conoce relativamente bien la evolución del edificio termal, ya que por el hecho de tener espacios a un nivel inferior (piscinas, hipocaustos, hornos), la estratigrafía y los restos se han conservado mejor. De todas formas, la existencia de un camino que cubre parte de las estructuras dificulta su interpretación. En líneas generales, podríamos decir que el edificio termal sufre una fase de crecimiento en época altoimperial, para contraerse en época tardía, detectándose también una progresiva elevación de los niveles de pavimentación.

Cuando a principios del siglo II se edificó la villa, ésta fue provista de un conjunto termal ubicado en el extremo sur. Se conoce de este primer momento una gran sala compartimentada con hipocausto y su correspondiente horno y, junto a ella, una gran piscina también calefactada con su horno: se trata del caldarium. Al otro lado del camino, una pequeña piscina debió formar parte del frigidarium, que permanece en buena parte por excavar.

A finales de la segunda centuria o ya a principios de la tercera se produjo una ampliación de las termas, con la construcción de tres salas que ocupan un ángulo del jardín interior, y un embellecimiento, del que es muestra evidente el mosaico de los peces que se situa en una sala del sector frío. Las tres nuevas salas presentan hipocausto, con entradas de aire y toberas o chimeneas en el interior de los muros. No obstante, no hay ningún horno para calefactarlas, por lo cual se ha supuesto que estos espacios, aunque fueron concebidos como salas calientes, nunca llegaron a funcionar como tales. Destaca un gran ámbito cuadrado con refuerzos de sillares en los ángulos, signo de una posible cubierta con bóveda de arista, y otro rematado por un ábside.

Frente a la tendencia expansiva mostrada en el período anterior, a partir del siglo IV se notará un proceso inverso, no sólo en el conjunto de la villa, sinó también en las termas. Las tres salas calefactadas construídas en la última reforma cambian de uso: la zona de hipocausto se convierte en vertedero doméstico y se sobreeleva el nivel del suelo para adecuar los ámbitos a nuevos usos, posiblemente de tipo residencial. Los materiales recuperados del vertedero proporcionan una cronología de primera mitad del siglo IV.

En la segunda mitad del siglo IV o a principios del $\vee$ se efectua una profundo cambio en la estructura del caldarium que se traduce en una drástica reducción de espacios, y que provoca una alteración del esquema funcional de las fases anteriores. En el interior de la gran sala compartimentada provista de hipocausto se construyen en este momento dos pequeñas salas cuadrangulares calefactadas que constan, cada una, de una pequeña bañera semicircular para uso individual. El horno correspondiente a este momento no ha sido localizado.

La última transformación detectada por los excavadores conlleva una reducción espacial todavía mayor y presenta una reutilización evi- 
dente de materiales antiguos $y$, en general, una calidad técnica inferior. Se conservan los dos ámbitos con hipocaustos de la fase anterior, pero se documenta una elevación de la cota del suelo y el abandono de los espacios semicirculares, así como la construcción de un nuevo horno. La cronología de esta última reforma no ha podido ser establecida, ya que se trata de una simple superposición arquitectónica. En cambio, los niveles de abandono se situan en el siglo VI aunque, dada la escasez de materiales cerámicos recuperados, quizás sean un poco posteriores.

Conocemos dos conjuntos termales construídos en el siglo I que pervivieron hasta los siglos IVN, pero ignoramos el destino que se les dió en el período bajoimperial. En la partida de El Cogoll, situada a medio camino de las poblaciones de Vilallonga del Camp y Alcover se encuentra una importante villa romana que nunca ha sido objeto de excavaciones sistemáticas. Las publicaciones se han limitado a referenciar los restos visibles en superficie: dos sepulcros monumentales y restos de unos muros que corresponden a unas termas. Estas últimas, fueron objeto de un estudio arquitectónico y planimétrico en el año 1984 (DUPRÉJULIÀ 1984), y de una excavación parcial el año siguiente (ANUARI 1993, 265).

Se trata de una construcción levantada con muros de opus caementicium sobre banquetas de cimentación, con sillares de refuerzo en las esquinas dispuestos de largo y de través alternadamente, la mayoría de los cuales han sido expoliados. El edificio consta de tres estancias alineadas en dirección norte-sur. La más sepentrional dispone de dos pequeños ábsides de planta externa cuadrangular, y la meridional muestra también un pequeño ámbito anejo rectangular. Se da como fecha para la construcción de estas termas el primer siglo de la era, y los niveles de abandono se datan en el siglo V.

La presencia de un ábside alineado con el eje del edificio hizo pensar a los excavadores en su posible interpretación como basilica paleocristiana -pensando quizás en el caso de Empúries, donde una basílica se superpuso a unas antiguas termas. No obstante, las catas realizadas, cuyos resultados no han sido debidamente publicados, se encargaron de rechazar esta hipótesis. No hay duda de que estamos ante un edificio termal. Como desconocemos el tipo de pavimento y las salas que disponen de hipocausto, el destino de cada ámbito debe darse de forma teórica, atendiendo a su disposición en la planta del edificio. La sala norte debe cumplir las funciones de apodyterium y frigidarium, con dos probables piscinas semicirculares. La intermedia debe ser un tepidarium, suponiendo que disponga de hipocausto, i la sala sur es con toda probabilidad el caldarium, con una pequeña piscina individual rectangular, que debió ser calefactada con un horno. Una segunda posibilidad es que la sala central sea en realidad un apodyterium. Aunque la funcionalidad originaria de esta construcción fue evidentemente termal, no sabemos si este uso pervivió hasta el siglo $\mathrm{V}$, momento en que se abandonó la construcción.

La villa de Mas dels Frares (Constantí) tiene una larga vida que empieza en el siglo II a.C. y termina en el siglo $\vee \circ \mathrm{Vl}$. Desde el año 1989 la Universitat Rovira i Virgili ha realizado diversas campañas de excavación (CORTÉS et alii 1991, LAUT 1993), centradas principalmente en el área termal, donde se han detectado diversos espacios que configuran un edificio de dimensiones considerables. De todas formas, el hecho de que gran parte de la construcción permanezca por excavar, la complejidad de las estructuras y las numerosas superposiciones, producto de un uso continuo, dificultan enormemente la interpretación de los ámbitos. El momento de fundación se situa en el cambio de era. El abandono, evidenciado por una capa de cenizas que cubre una de las piscinas mayores - una natatio de dos metros de profundidad- se data entre los siglos IV y $\mathrm{V}$, sin poder precisar más a causa del escaso material cerámico recuperado. Un segundo estrato de los siglos $\mathrm{V}$-VI acaba por terraplenar todo el espacio. Como en el caso de la villa de El Cogoll, se trata de unas estructuras alto-imperiales que continuan en funcionamiento hasta el Bajo Imperio, pero desconocemos para este segundo momento si las estancias siguieron teniendo un uso termal. 
Durante los años 1995-96 se llevaron a cabo importantes trabajos de excavación en el área residencial de la villa romana de Els Munts, y más concretamente en los brazos del ambulacro que limitan el hortus por el nordeste y estancias anejas. Los espectaculares hallazgos contribuyeron a un mayor conocimiento de todo el sector, aportando novedades notables para su correcta interpretación arquitectóni$\mathrm{ca}^{13}$. A pesar de concentrarse dichos trabajos en un sector muy concreto, algunos datos obtenidos pueden ser aplicados también a las denominadas termas inferiores.

En un artículo publicado por uno de nosotros hace ya algunos años (LÓPEZ 1993) estudiábamos el conjunto termal en función de los escasos datos disponibles y proponíamos la existencia de dos grandes fases constructivas; una a mediados de siglo II, y una ampliación que tendría lugar unos doscientos años después. El momento fundacional lo situábamos a partir de paralelos arquitectónicos, ya que el edificio sigue el modelo de lo que se ha venido en llamar termas con heliocaminus, cuyos máximos exponentes están en las homónimas de Villa Adriana y en las termas del Foro de Ostia, ambas de segundo tercio de siglo II. Lógicamente, consideramos que nuestras termas copiaban el modelo itálico y no a la inversa. Además, coincidía con uno de los momentos de esplendor de la villa, con C. Valerio Avito como propietario de la misma, cuya presencia está atestiguada epigráficamente. La segunda fase constructiva la datábamos a mediados del siglo IV en base a una serie de argumentos que nos parecieron suficientes: formando parte de un canal que proporciona el agua a una piscina del frigidarium que corresponde a la segunda fase se halló un fragmento de terra sigillata africana $C$ de la forma Lamboglia 40 (BERGES 1977: 41); los mosaicos que decoraban los suelos de algunas estancias son estilísticamente de los siglos III-IV (NAVARRO 1979); pero un hecho que nos pareció altamente significativo fue el hallazgo de un conjunto de cuatro monedas de mediados del IV, sellado por un pavimento de mosaico en un pequeño ámbito de paso (BERGES 1977: 44).

Estas dataciones han sido puestas en duda por los últimos excavadores del yacimiento, si bién admiten la existencia de las dos fases constructivas que habíamos propuesto. Para ellos, las termas inferiores habrían sido edificadas a finales del siglo I d.C., como el resto de la parte residencial, con una reforma a mediados del II, y destruídas sobre el 260, con el incendio que asoló la villa, y cuyas huellas son más que evidentes en determinados sectores. Suponen, pues, que estas termas sufrieron una evolución pareja a la que se ha documentado en la zona residencial.

Veamos a continuación en que se basa esta última hipótesis. Las excavaciones que realizó $M$. Berges en la parte residencial pusieron al descubierto un ámbito que en un determinado momento fue convertido en cisterna, después de haber excavado el subsuelo. Los nuevos trabajos han permitido descubrir las huellas de una pequeña fuente abastecida directamente por dicho depósito y, sobre ésta, una inscripción en la que puede leerse el siguiente texto:

\section{EX PRAECEPTO \\ AVITI ET FAVSTINAE.N.N. \\ CISTERNA.FACTA.LATA.P. \\ XIII.LONGA.P.XVII.ALTA.P.X.

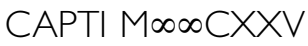

Bajo la fuente se encuentra el registro y una sola canalización que se dirige a las termas inferiores. Tanto la cisterna como la canalización quedaron cegadas con la ruína del incendio de mediados del III, y nunca más volvieron a ser utilizadas. Tomados objetivamente, con estos datos sabemos que C. Valerio Avito y Faustina mandaron construir a mediados del siglo II una cisterna para abastecer las termas inferiores, y que ésta quedó definitivamente inutilizada con la destrucción ocurrida sobre el 260.

\footnotetext{
13 Los resultados han sido recogidos en dos artículos, si bien en realidad el segundo es una ampliación del primero (Tarrats et alii 1997 y Tarrats et alii 1998).
} 
Los excavadores relacionan la cisterna con la segunda fase del edificio termal y suponen que la cisterna cegada supone necesariamente la inutilización definitiva de las termas.

Los autores no aportan nuevos datos para el momento fundacional del edificio, y a pesar de todo datan la construcción del edificio termal en el siglo I. Como parece excesivo que la villa disponga de tres conjuntos termales (las denominadas termas superiores, inferiores y de la playa), deciden eliminar el primero del cual, si bién no está excavado, hay indicios sufucientes para suponer su existencia ${ }^{14}$.

A mediados del siglo II se construyó la cisterna que conmemora la inscripción a que hemos hecho mención. Una cisterna que formaría parte del complejo sistema de abastecimiento de aguas a las piscinas de las termas inferiores. Así lo indica la presencia de otras canalizaciones que proveen el conjunto termal del líquido necesario, y que proceden de otros depósitos. El canal de la cisterna con inscripción conecta con otra conducción que a su vez abastece una de las piscinas del frigidarium, cuyo ábside fue construído en una segunda fase, pero no la totalidad de la piscina, que ya existía en la planificación originaria. Estas canalizaciones pudieron ser construídas para abastecer la piscina de la primera fase y no tienen porque relacionarse necesariamente con el ábside del segundo momento, cuando podrían haber sido reaprovechadas.

Sobre el 260/270 se produce el incendio generalizado de la villa que tan bién ha podido ser constatado en el área residencial. El incendio supuso la inutilización definitiva de la cisterna de C. Valerio Avito. Los excavadores afirman que este hecho supuso también el abandono total y definitivo de las termas inferiores, pero este dato implica solamente la inutilización de una de las cisternas que abastecían el conjunto termal. Una cisterna que no debió ser tan fundamental si -como afirman los autores del artículo- se abastecía de aguas pluviales (TARRATS et alii 1998: 215) ${ }^{15}$. No sabemos cómo afectó el incendio a nuestras termas. Creemos que escasamente, pues son edificios resistentes, con numerosas salas cubiertas con bóvedas y cúpulas y con pocos materiales combustibles en su interior. Además, M. Berges nunca mencionó en sus escritos la presencia de capas de incendio como las localizadas en el área residencial. A pesar de esto, los autores de la nueva hipótesis afirman, no sabemos con qué fundamento, que "les evidències obtingudes (...) també en el conjunt termal ens fan pensar que l'incendi (...) es va desenvolupar àmpliament per la vil.la" (TARRATS et alii 1998: 217).

Aunque el incendio del 260/270 supuso un paréntesis en la vida de la villa, hay indicios de nueva actividad partir de mediados del siglo IV. El sector residencial de la villa bajoimperial no ha sido localizado por ahora, pero sabemos que los restos del área residencial altoimperial fueron terraplenados. El hecho de que parte del yacimiento permanezca por excavar augura posibles sorpresas en este sentido. A mediados del IV se producen también reformas en las termas inferiores: es una prueba evidente la aparición de monedas de esta cronología bajo uno de los mosaicos, monedas que se omiten en el artículo ${ }^{16}$. ¿Cuál fue el alcance de

\footnotetext{
I4 Son una prueba los hipocaustos hallados en las excavaciones Sánchez Real (Sánchez 1971: 100) y Dupré (Dasca-Rovira 1991: 59). Estas salas deben relacionarse con un complejo termal y no con simples salas calefactadas (Tarrats et alii 1998: 2I5). Estas últimas se encuentran generalmente en domus o villae ubicadas en áreas geográficas con climas severos, y no acostumbran a hallarse en zonas de clima suave como aquí, donde son innecesarias (Degbomont 1984).

15 Conociendo la escasa e irregular pluviometría de nuestro clima es difícil pensar en un uso contínuo para el baño diario. Esta cisterna debe tomarse como una fuente de abastecimiento usada de forma complementaria en determinados momentos. Esto, suponiendo que el origen de sus aguas fuera exclusivamente pluvial. En este sentido, hay que destacar que la problemática del agua no está aclarada todavía. El mantenimiento de unas termas de tamaño medio como estas conllevan un gran consumo de agua que aquí sólo pudo ser solucionado mediante la construcción de un acueducto o con su extracción de pozos mediante norias. Es un aspecto no estudiado, pero seguro que el análisis en profundidad de los numerosos depósitos y canales presentes en el yacimiento darían la solución a la incógnita.

$16 \mathrm{Se}$ afirma que las únicas monedas que Berges ubica topograficamente son las halladas en los niveles de abandono de las piscinas
} del frigidarium (Tarrats et alii 1998: 200). 
estas reformas? Nosotros las habíamos relacionado con la segunda fase del edificio termal, pero con los nuevos hallazgos se introducen nuevos interrogantes. ¿Fueron restauradas las termas y convertidas en la parte residencial de la villa durante los siglos IV/N? No se detecta ninguna reforma en este sentido (por ejemplo, sería lógico pensar en el terraplenamiento de las piscinas para dejar todo el edificio a la misma cota, una nueva distribución de espacios con nuevos muros, etc.).

Parece que los niveles generales de abandono se situan en el siglo V. Hay que añadir un lote de bronces constantinianos que proporcionan una datación post quem y que debe entenderse como material residual en la singular circulación monetaria de la centuria siguiente (BERGES 1970b: 87). Finalmente, la excavación de un tramo de la cloaca principal de las termas proporcionó para su inutilización una cronología imprecisa de siglo IV (MACÍAS-RAMÓN 1998), pero el escaso material datable recuperado obliga a tomar este dato con cautela.

En definitiva, creemos que la cronología de la segunda fase de las termas inferiores no está todavía bien definida, y que nuevos datos sólo podrán ser obtenidos con la revisión del material recuperado por Berges y con la realización de sondeos estratigráficos que permitan, como mínimo, datar su primera construcción. Queda también por resolver el estudio de las termas superiores, por excavar, y las denominadas termas de la playa. Estas últimas parecen altoimperiales por el tipo de construcción, quizás del siglo I, pero sufrieron diferentes reformas y probablemente siguieron en uso en época bajo-imperial. Nuevamente se impone aquí una revisión de los materiales de las excavaciones realizadas por $M$. Berges.

\section{CONCLUSIÓN}

No vamos a entrar aquí en cuestiones de nomenclatura y usaremos el término villa para designar los establecimientos rurales a que haremos mención. Consideramos, además, que la presencia de un conjunto termal es un ele- mento lujoso y suficientemente significativo para aplicar esta denominación a los yacimientos que referiremos.

A pesar del estado general de desconocimiento de que adolece el mundo rural del entorno de Tarraco, tenemos localizadas una docena de villae que disponen de baños. Solamente unos, en la villa de El Moro, pueden ser considerados de época republicana. Este yacimiento tiene dos conjuntos termales. El más antiguo fue excavado en los años ochenta e interpretado como un conjunto de ámbitos pertenecientes a la parte residencial, pero una serie de elementos como concreciones calcáreas en los suelos y canales de desagüe permitieron su correcta identificación en la campaña de limpieza y documentación que llevamos a cabo en el año 1994. Se trata de un edificio sólo parcialmente excavado y que se ha datado entre finales del siglo II y el siglo I a.C., siendo amortizado en el cambio de era, cuando se construyeron unas nuevas termas en otra zona de la villa (TERRÉ 1983, 1987, 1993; PIÑOL 1996). La importancia de estas primeras termas viene determinada por la escasez de conjuntos termales tan tempranos en nuestro país.

Se conoce un buen número de villae altoimperiales provistas de conjuntos termales $y$, de hecho, casi todos pueden ser datados en los siglos I-II d.C. Algunos disponen de más de uno, como la gran villa de Els Munts (las denominadas termas superiores, inferiores y de la playa). La mayoría de baños tuvieron una más o menos larga perduración, de manera que pueden detectarse las diversas reformas a que los edificios fueron sometidos. Varias termas tienen su momento fundacional a partir de época augustea -segundas termas de El Moro, Mas dels Frares, L'Esquirol (RAMÓN 1990; 1993)y otras se construyeron en el siglo II -Repsol, Mas d'en Gras (SÁNCHEZ 1996), Callípolis.

A partir del siglo III se produce una transformación que presupone la desaparición de muchas villae, hecho que tradicionalmene se relacionó con las llamadas invasiones germánicas, pero cuya raíz está en cambios socioeconómicos mucho más profundos. El Camp de 
Tarragona no fue una excepción, y se constata cómo el número de villae bajo-imperiales es notablemente menor, con todo lo que ello supone. De forma pareja, disminuye también el número de termas. Conocemos para el siglo IV tres conjuntos termales es uso: Repsol, Centcelles y Callípolis. Otros, como El Cogoll y Mas dels Frares plantean dudas: las estructuras continuaron utilizándose hasta el siglo $\mathrm{V}$, pero desconocemos si mantuvieron un uso termal o cambiaron de función.

Lo que sí podemos afirmar con rotundidad es que el gran momento de expansión para los baños en las villae del ager tarraconensis fue el alto imperio, con una decena de establecimientos detectados, frente a uno solo de época republicana y entre tres y cinco de época tardía. Consideramos que la excavación de nuevos yacimientos acabará por confirmar esta tendencia.

Se detectan unas importantes transformaciones de todos los complejos termales tardíos en relación con los alto imperiales. Se plasman en general en una constante evolución hacia la reducción en las dimensiones de los mismos, una tendencia clara a la polifuncionalidad de los sectores fríos (apodyteriumfrigidarium) y a una proliferación de bañeras individuales en los sectores calientes en sustitución de los alvea de mayores dimensiones típicos de época precedente ${ }^{17}$. Quizás pueda verse en ello una preocupación por un mayor ahorro de agua y leña. No podemos olvidar lo que suponía la obtención de los recursos necesarios para el funcionamiento general y el mantenimiento de estos complejos. El abastecimiento de materias primas, sobretodo madera y agua, jugaron un papel muy importante en el momento de su construcción. Qui- zás pueda plantearse aquí si este hecho responde a causas económicas o de otro tipo, como una creciente desforestación de los bosques más próximos.

De todas formas, no sabemos mucho más. Algunas excavaciones antiguas fueron realizadas deficientemente y con pocos medios, de forma que la información de que disponemos es casi nula -Altafulla, Mas de Valls (CARRERAS 1945)-; en otras, al edificio termal se le atribuyó otro destino -por ejemplo, el caso ya citado de El Moro, o el de La Llosa, que fue confundido con una factoría de salazones (MACÍAS/RAMÓN 1993; GARCÍAJPUCHE 1999). Finalmente, algunas excavaciones han sido publicadas de forma incompleta (Els Munts, El Cogoll). Otras, muy recientemente excavadas, estan siendo objeto de estudio (Els Masos, Hort del Pelat). Debemos hacer hincapié en un caso específico: la importante villa excavada en 1996 en terrenos de Repsol Química, que se halló muy bien conservada y disponía de dos conjuntos termales. El interés del yacimiento fue silenciado desde un principio, y a su rápida excavación sucedió una todavía más rápida destrucción, sin que por el momento los excavadores hayan publicado absolutamente nada, a pesar de su evidente interés científico ${ }^{18}$. Con todos estos problemas, un estado de síntesis sobre el estado de la cuestión de los conjuntos termales en las villae del Campo de Tarragona deriva forzosamente a unos resultados bastante pobres. No obstante, en un primer trabajo realizado en 1993 se estudiaban ya en profundidad algunos restos (por ejemplo, las termas inferiores de Els Munts y Centcelles). Las nuevas excavaciones realizadas desde entonces (Mas d'en Gras, Callípolis, Els Masos, Hort del Pelat) auguran sin duda para un futuro no muy lejano un panorama más alentador.

Tarragona, 20 de junio de 2000.

\footnotetext{
17 La única excepción sería la ampliación de las termas inferiores de Els Munts, suponiendo que la cronología que proponemos para la segunda fase sea acertada.

18 Los resultados se hallan en Menchón-García 1997. Se trata de una villa cuyos primeros momentos son de época republicana y parece tener una vida hasta el siglo V. Aquí se encuentran dos conjuntos termales. El primero se edificó a finales del siglo ll y perduró hasta mediados del IV, momento en que se construyó el segundo conjunto, situado más al norte, cuyos niveles de abandono se situan en el primer cuarto del siglo V. Al estar estos trabajos inéditos no podemos realizar un estudio más concreto ni presentar la planimetría correspondiente.
} 


\section{APÉNDICE \\ CUADRO DE LOS CONJUNTOS TERMALES \\ EN LAS VILLAS DEL CAMP DE TARRAGONA}

\begin{tabular}{|c|c|c|c|c|}
\hline Yacimiento & Municipio & República & Alto imperio & Bajo imperio \\
\hline El Moro & Torredembarra & $x$ & $x$ & -- \\
\hline Altafulla & Altafulla & $s / d^{*}$ & $s / d$ & $s / d$ \\
\hline Els Munts & Altafulla & -- & $x$ & $?$ \\
\hline Centcelles & Constantí & -- & -- & $x$ \\
\hline Mas dels Frares & Constantí & -- & $x$ & $?$ \\
\hline REPSOL & El Morell & -- & $x$ & $x$ \\
\hline El Cogoll & Vilallonga & -- & $x$ & $?$ \\
\hline Callípolis & Vila-seca & -- & $x$ & $x$ \\
\hline Mas d'en Gras & Vila-seca & -- & $x$ & -- \\
\hline L'Esquirol & Cambrils & -- & $x$ & -- \\
\hline La Llosa & Cambrils & -- & $x$ & -- \\
\hline Els Masos & Cambrils & -- & $x$ & -- \\
\hline Mas de Valls & Reus & $s / d$ & $s / d$ & $s / d$ \\
\hline Hort del Pelat & Riudoms & $s / d$ & $s / d$ & $s / d$ \\
\hline
\end{tabular}

\section{BIBLIOGRAFÍA}

ALFÖLDY, G. 1975: Die römischen Inschriften von Tarraco. Madrider Forschungen, 10. Berlin.

AMO, Ma. D. del 1979: Estudio crítico de la necrópolis paleocristiana de Tarragona. Institut d'Estudis Tarraconenses Ramon Berenguer IV. Tarragona.

Anuari 1993: Edifici de planta basilical, Vilallonga del Camp, en Anuari d'intervencions arqueològiques a Catalunya, I. Època romana i antiguitat tardana. Campanyes 1982-1989. Barcelona, 265

ADSERIAS, M. et alii 1997: La transformació urbana de Tàrraco al segle IV d.C. Noves dades arqueològiques, en Annals de l'Institut d'Estudis Gironins, XXXVI. Girona, 923937.

AQUILUÉ, X. 1991: Relaciones económinas, sociales e ideológicas entre el norte de África y la Tarraconense en época romana. Las cerámicas de producción africana procedentes de la Colonia Iulia Urbs Triumphalis Tarraco. Tesis doctoral inédita. Barcelona.

ARCE, J. 1986: El último siglo de la España romana (284409), Madrid.

ARCE, J. 1995: Constantinopla, Tárraco y Centcelles, en Butlletí Arqueològic RSAT, I6, I47-165.

BALIL, A., MONDALO, R. 1985: El mosaico con representación de peces hallado en las proximidades de Tarragona, en Boletín del Seminario de Estudios de Arte y Arqueologia, vol. II, 25।-256.

BERGES, M. 1970a: Informe sobre Els Munts, en Boletín Arqueológico RSAT, I40-150.

BERGES, M. 1970b: Las ruinas de Els Munts (Altafulla, Tarragona), en Informació Arqueològica, 3, 81-87.

BERGES, M. 1977: Nuevo informe sobre Els Munts, Centre d'Estudis Altafullencs, I, 27-47.

BRÖDNER, E. 1983: Die Römischen Thermen und das Antike Badewesen. Darmstadt.

CARRERAS, M. 1945: Los hallazgos arqueológicos de Pórporas (Reus), en Boletín Arqueológico RSAT, 82-91.

CARRETÉ, J. Ma., KEAY, S., MILLETT, M. 1995: A roman Provincial Capital and its hinterland. The Survey of the territory of Tarragona, Spain, 1985-1990, en JRA, Suppl. I5. Ann Arbor. 
CHAVARRÍA, A. 1996: Transformaciones arquitectónicas de los establecimientos rurales en el nordeste de la Tarraconensis durante la antigüedad tardía, en Butlletí de la Reial Acadèmia Catalana de Belles Arts de Sant Jordi, X, 165-202.

CORTÉS, R. et alii |99|: Resultats de la primera campanya d'excavació del Mas dels Frares de Constantí (juliol de 1989), a Butlletí Arqueològic RSAT, 13, 1991, 69-82.

DASCA, A., ROVIRA, J. 1991: Aproximació a la investigació de la historia antiga del Baix Gaià i conclusions de l'estudi del món indígena i el seu procés evolutiu des de l'arribada dels romans fins a les invasions del segle III dC, Centre d'Estudis d'Altafulla, Tarragona.

DEGBOMONT 1984: Le chauffage par hypocauste dans l'habitat privé, ERAUL, Liège.

DUPRÉ, X. 1994: L'arc romà de Berà (Hispania Citerior). Institut d'Estudis Catalans. Barcelona.

DUPRÉ, X., JULIÀ, M. 1984: Un edifici de planta basilical a Vilallonga del Camp (Tarragonès), en Informació Arqueològica, 42, 58-61.

GARCÍA, M., PUCHE, J. M. 1999: La Llosa, una nova excavació, en Revista de Cambrils, $n^{\circ}$ 338, 45.

HAUSCHILD, Th. 1965: Vorberich über Arbeiten in Centcelles 3, en MM, 6.

HAUSCHILD, Th., SCHLUNK, H. 1986: La vil.la romana i el mausoleu constantinià de Centcelles. Fòrum, 5. Tarragona.

HAUSCHILD, Th., ARBEITER, A. 1993: La villla de Centcelles. Tarragona.

HAUSCHILD, Th. 1994: Murallas de Hispania en el contexto de las fortificaciones del área occidental del Imperio Romano, en Actas del XIV Congreso Internacional de Arqueología Clásica. La ciudad en el mundo romano. Tarragona, 1993. Vol. I, 223-232.

JÁRREGA, R. 1997: El poblamiento rural en el este de la Tarraconense en época teodosiana, en Congreso Internacional La España de Teodosio, vol II, 533-542.

KEAY, S. 1984: Late Roman Amphorae in the Western Mediterranean. A tipology and economic study: the catalan evidence. BAR International Series, 196.

KEAY, S. 1987: The Impact of the Foundation of Tarraco upon the indigenous settlement pattern of the ager tarraconensis, en Primeres Jornades Internacionals d'Arqueologia Romana (Granollers, 5-8 de febrero 1987). Granollers, 53-58.

LAUT 1993: Mas dels Frares (Constanti), en R. Mar/]. López/LI. Piñol (eds.): L'abastament d'aigua a les ciutats romanes, DAC, 0, 1993, 100-103.

LÓPEZ, J. 1993: Les termes inferiors de la vil·la romana dels Munts, en R. Mar/J. López/LI. Piñol (eds.): L'abastament d'aigua a les ciutats romanes, DAC, 0, 1993, 5679.
LÓPEZ, J. 1997: Un nuevo conjunto paleocristiano en las afueras de Tárraco, en Revista de Arqueología, 197 (Septiembre 1997), 58-64.

LÓPEZ, J., PIÑOL, LI. 1998: Tarragona romana, en El món de l'aigua. Història de l'abastament d'aigua a Tarragona Tarragona, 19-50.

MACÍAS, J. Ma. 1996: Memòria de l'excavació arqueològica a la Villla romana del Torrent de Vallmoll. Pk 14.500 de la N-240 (Vallmoll, Alt Camp). Memoria entregada al Departament de Cultura de la Generalitat de Catalunya. Tarragona. Inédita.

MACÍAS, J. Ma 1999: Memòria de la intervenció arqueològica realitzada a la villla romana de Callípolis (Vilaseca, Tarragonès). Memoria entregada al Departament de Cultura de la Generalitat de Catalunya. Tarragona. Inédita.

MACÍAS, J. Ma., RAMON, E. 1993: La vil·la romana de La Llosa, Cambrils (Baix Camp), en Butlletí Arqueològic RSAT, 15, 357-373.

MACÍAS, J. Ma., RAMON, E. 1999: Memòria de les actuacions arqueològiques efectuades a la vil·la romana dels Munts (Altafulla, Tarragonès). Anys 1995-1998. Memoria entregada al Departament de Cultura de la Generalitat de Catalunya. Tarragona. Inédita.

MACÍAS, J. M., TUSET, F. 1995: Excavacions arqueològiques a la vil·la romana de Cal-lipolis (Vilaseca, Tarragonès), en Tribuna d'Arqueologia 1994-1995. Barcelona, I13-121.

MENCHÓN, J. J., GARCÍA, M. 1997: Memòria de la intervenció arqueològica duta a terme a la vil.la de Repsol Química (El Morell, Tarragonès). Memoria entregada al Departament de Cultura de la Generalitat de Catalunya. Tarragona. Inédita.

MIRET, M., SANTMARTí, J., SANTACANA, J. 199।: From indigenous structures to the Roman World: models for the occupation of Central Coastal Catalunya, en G. Barker \& J. Lloyd (Eds.): Roman Landscape archaeological survey in the Mediterranean region. London, 47-53.

MIRÓ, J. 1985: Les fonts escrites i el vi del Conventus Tarraconensis, en Pyrenae, 21, 105-112.

MIRÓ, J. 1988: La producción de ánforas romanas en Catalunya. Un estudio sobre el comercio del vino de la Tarraconense (sig/o I a.C.-I d.C.). Oxford. BAR International Series, 473

NAVARRO, R. 1979: Los mosaicos romanos de Tarragona. Tesi doctoral. Universitat de Barcelona. Inédita.

NIERHAUS, R. 1964: Baedro. Topografische Studien zum Territorium des Conventus Cordubensis in der Mittleren Sierra Morena, en MM, 5, 185-212.

NIELSEN, I. 1990: Thermae et Balnea. The architectural and cultural history of Roman Public Baths. Aarus University Press.

OLESTI, O. 1997: Els primers productors d'àmfores vinícoles al Maresme (s. I a.C.), en Annals de l'Institut d'Estudis Gironins, vol. XXXVI. Girona, 425-448. 
PÉREZ, A. 1997: La época de Teodosio y sus inmediatas en el oeste de Cataluña, en Congreso Internacional La España de Teodosio, vol II, 605-6I4.

PIÑOL, LI. 1993: El conjunto termal de Centcelles (Constantí), R. Mar, J. López, LI. Piñol (eds.): L'abastament d'aigua a les ciutats romanes, DAC, 0, 1993, 84- 100.

PIÑOL, LI. 1996: Memòria de la intervenció arqueològica a la vil.la romana del Moro (Torredembarra). Campanya 1994. Memoria entregada al Departament de Cultura de la Generalitat de Catalunya. Tarragona. Inédita.

RAMON, E. 1990: La villa romana de l'Esquirol, Cambrils (Baix Camp), a Butlletí Arqueològic, 12, 1990, 193 194.

RAMON, E. 1993: L'Esquirol, Cambrils, en Anuari d'intervencions arqueològiques a Catalunya, I. Època romana I antiguitat tardana. Campanyes 1982-1989. Barcelona, 49-50.

REMOLÀ, J. A. 2000: Las ánforas tardo-antiguas en Tárraco (Hispania Tarraconensis). Siglos IV-VIII d.C. Barcelona.

REVILLA, V. 1993: Producción cerámica y economía rural en el bajo Ebro en época romana. El alfar de l'Aumedina, Tivissa (Tarragona). Col.lecció Instrumenta, I. Barcelona.

REVILLA, V. 1995: Producción artesanal, viticultura y propiedad rural en la Hispania Tarraconense, en Gerion, I3, 305-338.

REYNOLDS, P. 1987: El yacimiento tardorromano de Lucentum (Benalua, Alicante). Las cerámicas finas. Alicante.

ROSSER, P. 1994: Nuevas aportaciones a la problemática de la antigüedad tardía en Alicante, LQNT, 2, 69-I I0
SÁNCHEZ, E. 1996: L'arquitectura dels banys privats: un exemple a la vil.la romana del Mas d'en Gras (Vila-seca, Tarragonès), en Tribuna d'Arqueologia, 1995-1996, I65- 175.

SÁNCHEZ, J. 1971: Los restos romanos de Els Munts. Altafulla. Tarragona, Institut d'Estudis Tarraconenses Ramon Berenguer IV. Tarragona.

SÁNCHEZ, J. 1990: "En busca de Callipolis", en Treballs Canongins, 7, I33-175.

TARRATS, F., MACÍAS, J. M‥, RAMON, E. 1997: Noves intervencions a la vil la romana dels Munts (Altafulla, Tarragonès), en Tribuna d'Arqueologia, 1996-1997, 35-56.

TARRATS, F., MACÍAS, J. M‥, RAMON, E., J. M‥ REMOLÀ 1998: Excavacions en l'àrea residencial de la vil la romana dels Munts (Altafulla, Tarragonès), en Empúries, 51, $197-$ 225.

TERRÉ, E. 1983: El Moro, en Arqueología 83, Barcelona, 196.

TERRÉ, E. 1987: La villa del Moro (Torredembarra): un exemple de poblament rural al Camp de Tarragona, en Primeres Jomades Internacionals d'Arqueologia Romana (Granollers, 5-8 de febrero de 1987). Granollers, 1987, 217-224.

TERRÉ, E. 1993: La vil·la romana de "El Moro" (Torredembarra), R. Mar, J. López, LI. Piñol (eds.): L’abastament d'aigua a les ciutats romanes, DAC, 0, 1993, 79-84.

VILASECA, A., CARILLA, A: L'assentament romà de La Clota, Creixell, Tarragonès. El poblament rural al nordest del Tarragonès en context de canvi d'Era, a Citerior, 2, |89-20।.

YEGÜL, F. 1992: Baths and bathing in Classical Antiquity. Massachusets. 


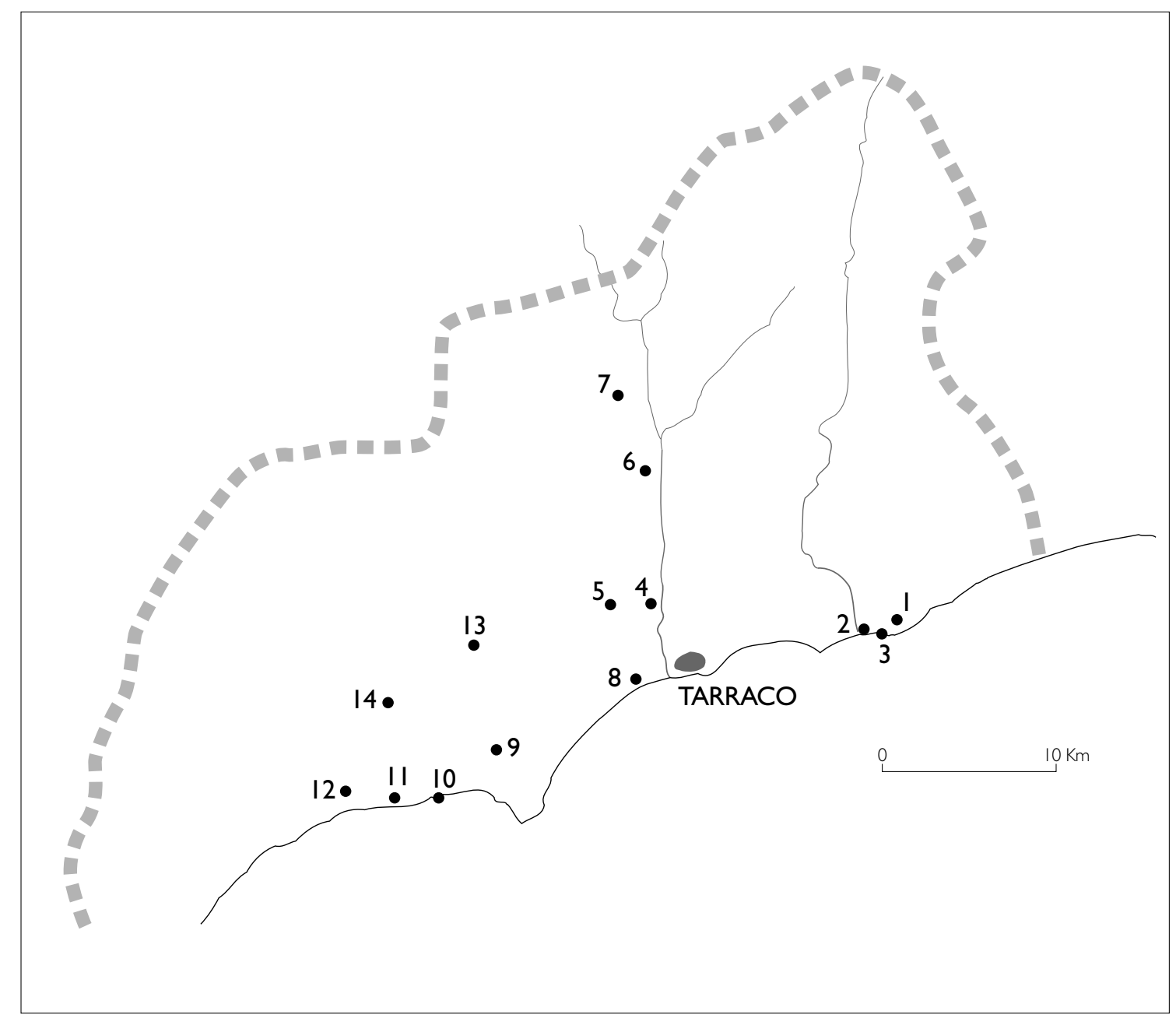

Fig. I. Mapa del Camp de Tarragona, con la situación de Tarraco y de las villae que presentan conjuntos termales (Dibujo: Oscar Curulla).

Explicación del mapa:

$\begin{array}{lll}\text { Núm. } & \text { Yacimiento } & \text { municipio } \\ 1 & \text { El Moro } & \text { Torredembarra } \\ 2 & \text { Altafulla } & \text { Altafulla } \\ 3 & \text { Els Munts } & \text { Altafulla } \\ 4 & \text { Centcelles } & \text { Constantí } \\ 5 & \text { Mas dels Frares } & \text { Constantí } \\ 6 & \text { REPSOL } & \text { El Morell } \\ 7 & \text { El Cogoll } & \text { Vilallonga } \\ 8 & \text { Callípolis } & \text { Vila-seca } \\ 9 & \text { Mas d'en Gras } & \text { Vila-seca } \\ 10 & \text { L'Esquirol } & \text { Cambrils } \\ 11 & \text { La Llosa } & \text { Cambrils } \\ 12 & \text { Els Masos } & \text { Cambrils } \\ 13 & \text { Mas de Valls } & \text { Reus } \\ 14 & \text { Hort del Pelat } & \text { Riudoms }\end{array}$




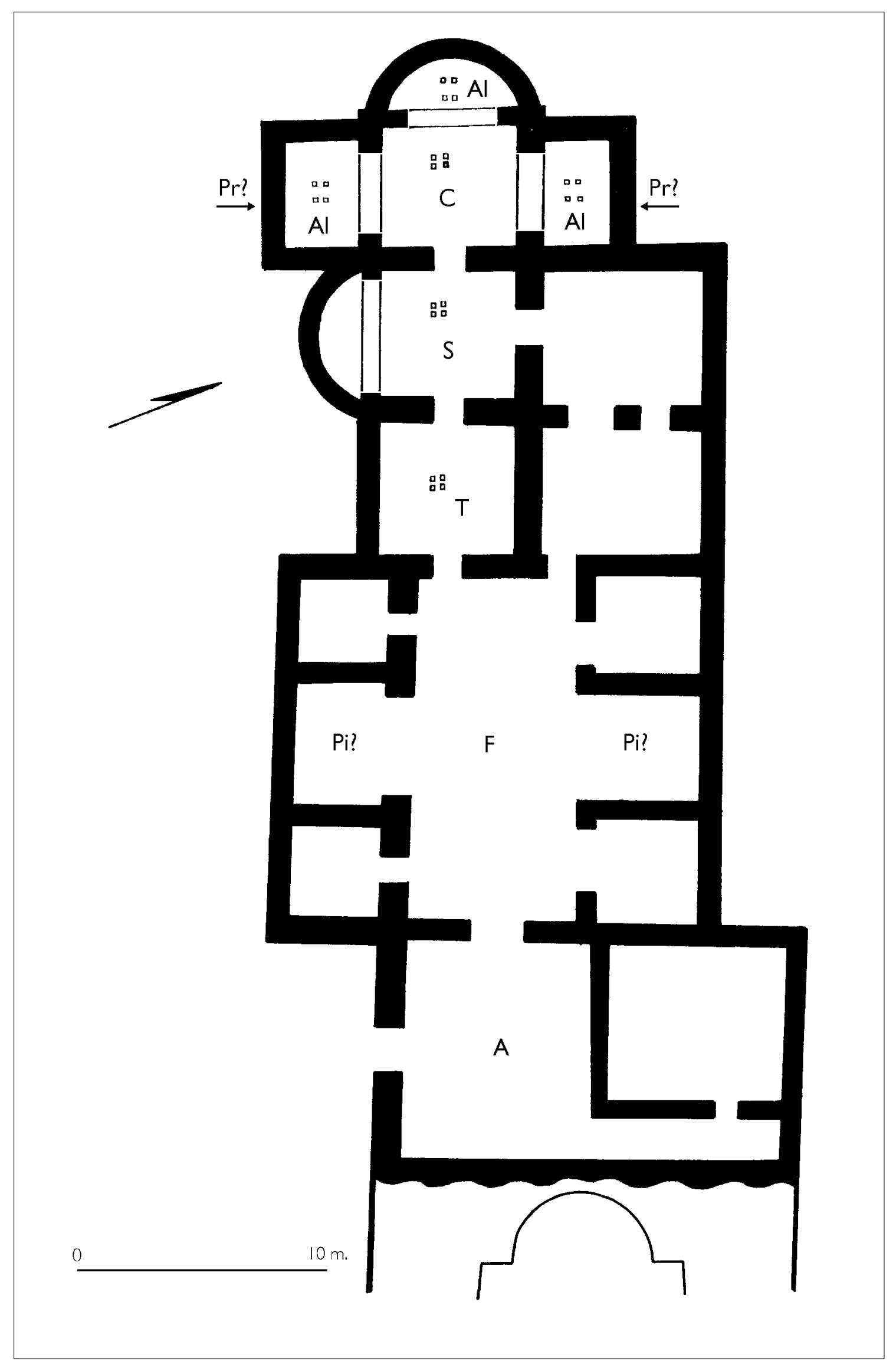

Fig. 2. Centcelles, primer conjunto termal (Dibujo: Oscar Curulla). 


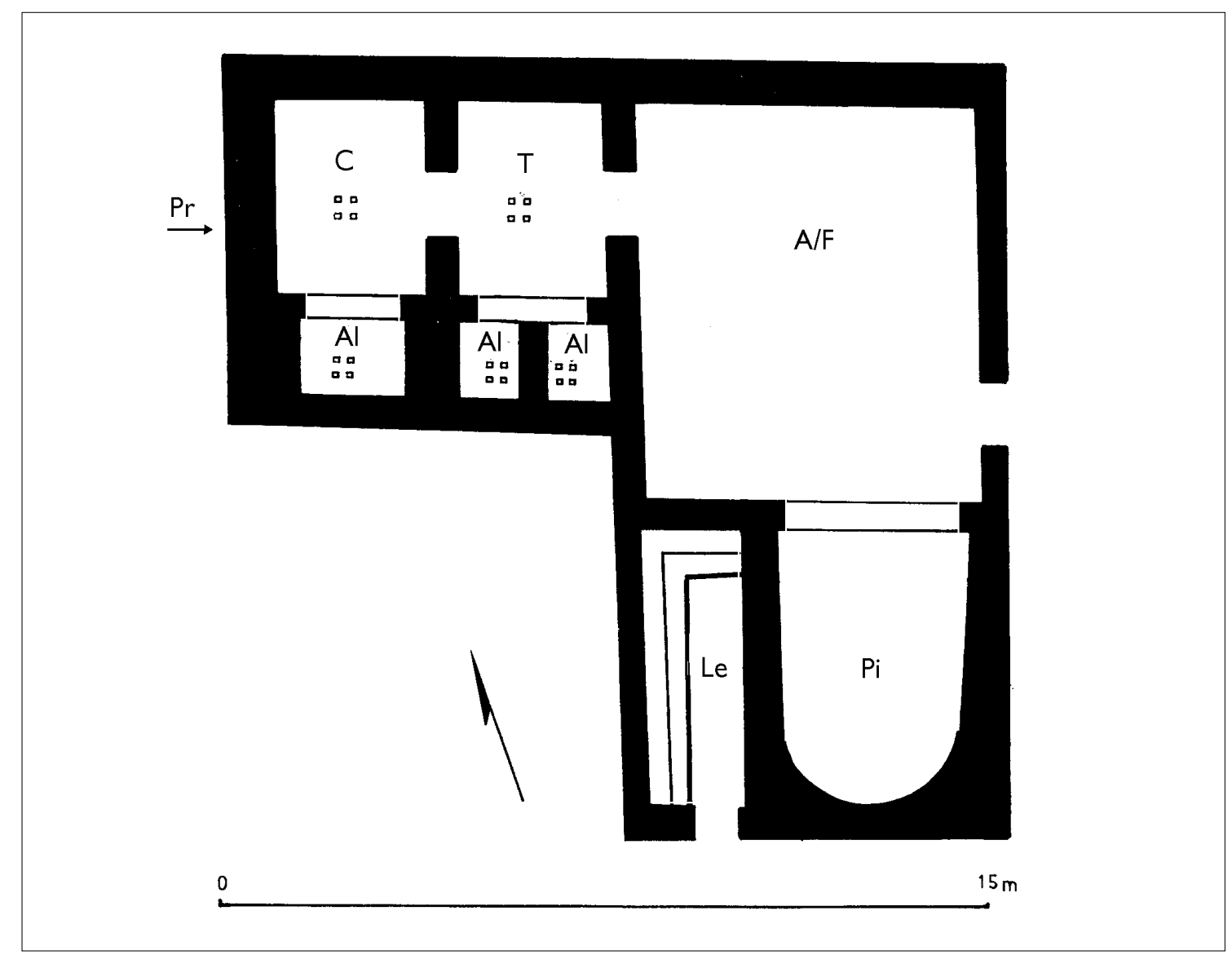

Fig. 3. Centcelles, segundo conjunto termal (Dibujo: Oscar Curulla).

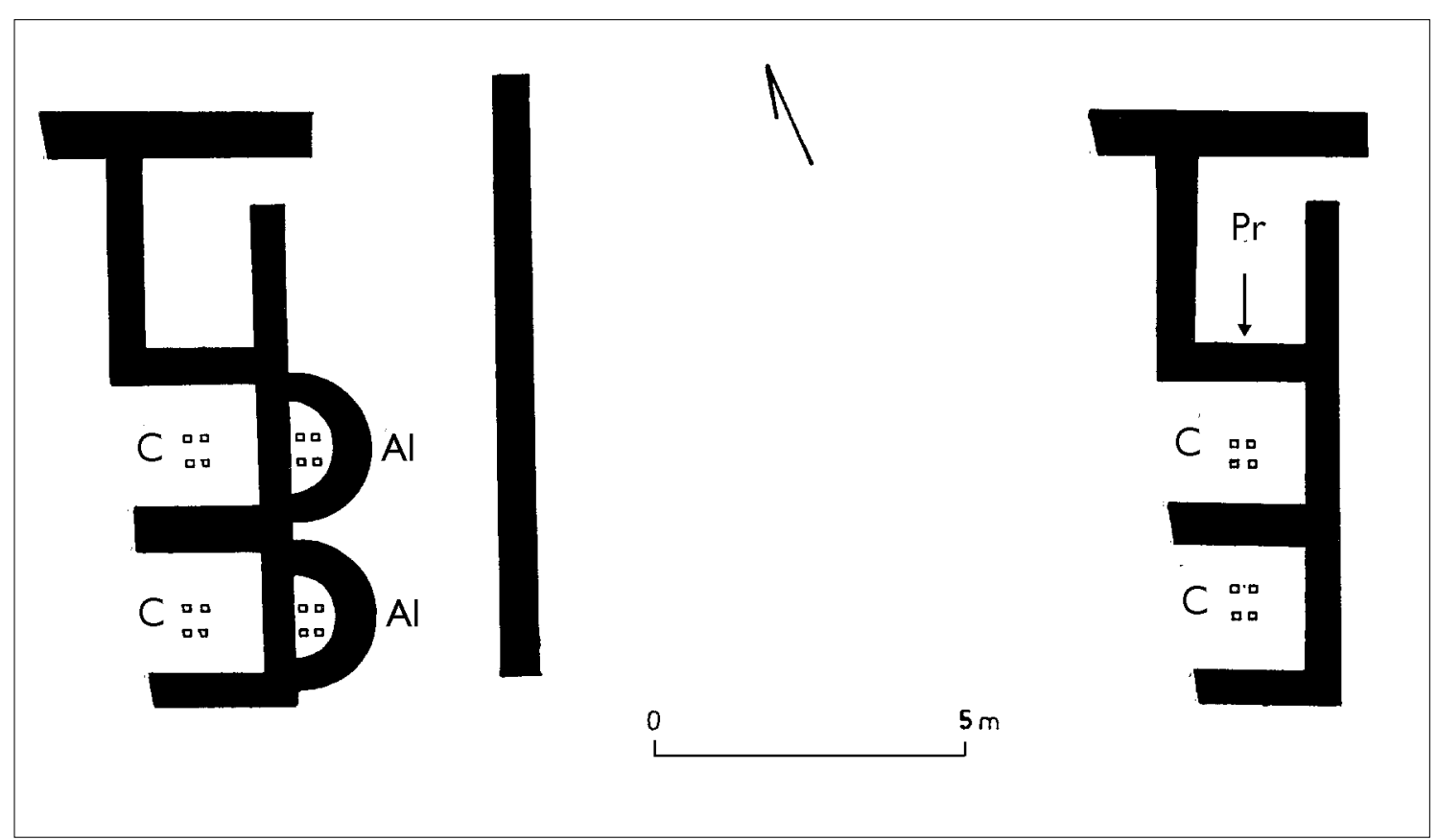

Fig. 4. Callípolis. Tercera y cuarta fase del complejo termal según Macías/Tuset 1995 (Dibujo: Oscar Curulla). 